Int. J. Electrochem. Sci., 15 (2020) $8241-8252$

International Journal of

ELECTROCHEMICAL

SCIENCE

WwW.electrochemsci.org

\title{
Study on Manganese Dioxide/Loofah-Activated Carbon Supercapacitors
}

\author{
Lin Hu*, Yating Pan, Shuai Liu, Lifang Jiang, Qujin Cui, Yijia Huang, Juan Tang, \\ Jianping Liu ${ }^{l}$, Wenyuan Xu \\ School of Material Science and Engineering, East China JiaoTong University, Nanchang 330013, \\ China; \\ *E-mail: $\underline{\text { Hulin21@ hotmail.com }}$
}

doi: $10.20964 / 2020.08 .85$

Received: 25 March 2020 / Accepted: 8 June 2020 / Published: 10 July 2020

\begin{abstract}
The selection of appropriate carbon and loading materials and their corresponding preparation methods is necessary for obtaining high-quality supercapacitors. This paper used loofah as a raw material to prepare a kind of super activated carbon with a large specific surface area. Manganese dioxide was precipitated on the super activated carbon of the loofah using a solution precipitation method to prepare a manganese dioxide/super activated carbon composite electrode material. Scanning electron microscopy and X-ray diffraction were used to characterize the composite electrode materials. It was found that the loofah activated carbon had a porous composite structure, and manganese dioxide was loaded on the activated carbon as an amorphous structure. Cyclic voltammetry (CV), constant current charge and discharge (GCD), and AC impedance methods were used to study the electrochemical behaviour of the prepared composite electrode materials in $\mathrm{KOH}$ and $\mathrm{Li}_{2} \mathrm{SO}_{4}$ electrolytes. The manganese dioxide/super activated carbon composite electrode material was used to assemble a supercapacitor, and its specific energy and specific power were measured by constant current charge and discharge. The electrochemical stability was tested by the application of multiple cycles of high current charge and discharge. When the electrolyte was a $6.0 \mathrm{~mol} / \mathrm{L}$ potassium hydroxide solution, the current density was $1.25 \mathrm{~A} / \mathrm{g}$, and the measured specific capacitance was as high as $472.66 \mathrm{~F} / \mathrm{g}$.
\end{abstract}

Keywords: supercapacitors; activated carbon; manganese oxide; composite materials; electrochemical properties

\section{FULL TEXT}

(C) 2020 The Authors. Published by ESG (www.electrochemsci.org). This article is an open access article distributed under the terms and conditions of the Creative Commons Attribution license (http://creativecommons.org/licenses/by/4.0/). 